\title{
Ensayos de eficiencia con macrófitas para la remoción de carga contaminante en aguas residuales de hatos lecheros para un subsector de la Laguna de Fúquene ${ }^{1}$
}

Luís Francisco Rodríguez R.2, Yoldi Dalila Ortiz Muñoz ${ }^{2}$. Hernando Navarro Chaparro², Helmut Espinosa Garcia ${ }^{3}$, Vilma Hernandez Montaña ${ }^{4}$, ttomacrofitas@yahoo.com.ar

\section{RESUMEN}

El proyecto de investigación se desarrolló en dos fases. En la primera fase se realizó la caracterización de las aguas residuales de dos hatos lecheros ubicados en el municipio de Susa (Cundinamarca), subsector de la laguna de Fúquene. El hato lechero "Las delicias" se determinó como el vertimiento más crítico, usando sus residuos líquidos orgánicos para alimentar el sistema de humedales artificiales implementado en la segunda fase, en la cual se evaluaron en escala piloto los porcentajes de remoción de materia orgánica y nutriente tales como $\mathrm{DBO}_{5}, \mathrm{DOO}, \mathrm{NO}_{3}, \mathrm{PO}_{4}$ y Sólidos totales. Como base del ensayo fueron empleadas las especies macrófitas Eichhornia crassipes (Buchón).

Proyecto de Investigación del Grupo PROGASP de la Tecnología en Gestión Ambiental y Servicios Públicos de la Universidad Distrital.

2 Coinvestigador Tecnólogo en Saneamiento Ambiental.

3 Director. Ingeniero Forestal. Esp. Planificación del Desarrollo. Profesor de Conservación de cuencas y suelos.

4 Coinvestigadora ingeniera Química. Magíster. en gestión ambiental del desarrollo. Profesora de calidad de aguas Facultad del medio ambiente y recursos naturales. 
Limnobium laevigatum (Hoja flotante) y Typha domingensis (Enea), extraídas de la laguna de Fúquene. Los resultados obtenidos a partir del análisis estadístico, empleando un diseño experimental de bloques simples al azar, indican que Eichhornia crassipes reportó mayor eficiencia en la remoción de carga orgánica (65\%) para este tipo de residuos líquidos.

\section{Palabras claves:}

Fitorremediación, Humedales artificiales, hatos lecheros, macrófitas, remoción, residuos líquidos orgánicos.

\section{ABSTRACT}

This research project was developed in two phases. In the first phase the wastewater characterization was made in two milk's production farms located in Susa (Cundinamarca), section of Fuquene's lagoon. The farm named "Las delicias" was determined as the most critical point; using their organic liquid residues to feed the wetlands system implemented in the second phase, in which the organic matter removal percentages and nutritious such as: $\mathrm{BOD}, \mathrm{COD}, \mathrm{NO}_{3}, \mathrm{PO}_{4}$ and total solids were evaluated using a pilot scale. The macrophytes species used as base of the practice were Eichhomia crassipes (Buchón), Limnobium Laevigatum (floating leaf) and Typha domingensis (Eneal, extracted of Fuquene's lagoon. The statistical analysis was made using a random simple block system and it shows that Eichhornia crassipes has a bigger efficiency in the organic load removal (65\%) for these kind of liquid residues.

Key words:

Phytoremediation, milk's production farm, macrophytes, removal, organic liquid. residues and wetlands.

\section{INTRODUCCIÓN}

La ganadería de leche, en los valles de Ubaté y Susa, es la principal fuente de ingresos y a su vez la principal fuente de contaminación en la cuenca hidrográfica de la laguna de Fúquene. Esta área es affectada.por dos fuentes contaminantes clasificadas en puntuales (vertimientos directamente a cuerpos de agua) y no puntuales. Las cargas contaminantes no puntuales escurren sobre los campos o por medio de pequeños canales - banquetas a los ríos y lagunas. Las haciendas ganaderas bombean el exceso de aguas lluvias a los canales del distrito de riego, y a los ríos y quebradas liberando gran cantidad de desechos orgánicos a los tributarios de la laguna de Fúquene (Santos M. 2000).

La rata de escorrentía de carga contaminante aportada a la laguna por la actividad ganadera, bajo las condiciones actuales, según el estudio de la JICA - CAR (1998 - 2000). provee un aporte de $65.2 \%$ para la DBO, $80.6 \%$ para la DOO, $60.5 \%$ para el total de nitrógeno y un $75.5 \%$ para el total de fósforo. Existe una relación directa entre el nivel 
de escorrentía de cargas contaminantes y el incremento de la DBO y DOO en los cuerpos de agua, acelerando el deterioro de los mismos.

En la fase inicial del de la presente investigación se realizó la caracterización de las aguas residuales de dos hatos lecheros ubicados en el municipio de Susa (Cundinamarca), vereda Punta de Cruz, como referente para reportar la calidad actual de los vertimientos. Este tipo de agroindustriàs descargan los vertimientos (en mayor porcentaje heces vacunas, mezcladas con el agua residual proveniente del lavado de los equipos mecánicos de ordeño junto con residuos de detergentes y desinfectantes), sin ningún tipo de tratamiento sobre los potreros de pastöreo, una vez colmatado el pozo estercolero.

Parte de las excretas están sometidas a una degradación natural donde inicialmente la entomofauna, bacterias y hongos, van consumiendo éstas variando en función de las condiciones aerobias o anaerobias. Un remanente permanece sobre el pastizal y va evolucionando en función de las condiciones ecológicas del lugar: clima, estación, vegetación, pisoteo, pendiente etc. Esta degradación puede ser.contaminante o potencialmente contaminante al ser interrumpida por condiciones climatológicas adversas, y al ser arrastrados parte de éstos vertimientos por escorrentía superficial sin haber sufrido una evolución completa, generan en algunos casos, saturación del suelo y pérdidas por escorrentía, y en otros, la no saturación del suelo ocasionando pérdidas por infiltración y percolación, al igual que sobrecargas de fertilizantes en ciertos periodos del año ocasionando contaminación en los pastizales por exceso de nutrientes.

En investigaciones anteriores, empleando plantas acuáticas en tratamientos de aguas residuales domésticas, se reportaron eficiencias aproximadas de un 80 a $95 \%$ en remoción de DBO, DOO, Nitrógeno y fósforo (Seoanes. M. 1999). Sin embargo para las características de los vertimientos de hatos lecheros dentro del área de la cuenca hidrográfica de la laguna de Fúquene, no se han realizado estudios de este tipo; por lo tanto como segunda fase del proyecto, se determinó desarrollar ensayos de fitorremediación dentro de un esquema de humedales artificiales, como una alternativa que ofrece un mínimo gasto energético, bajo impacto ambiental, alta efectividad y economía de mantenimiento, para el tratamiento de residuos orgánicos líquidos de este tipo.

La evaluación se planteo mediante la construcción y seguimiento de un sistema a escala piloto en condiciones ambientales similares a las del área de estudio, identificando el porcentaje de remoción por parte de las macrófitas Eichhornia crassipes, typha domingensis y Limnobium laevigatum, lespecies que crecen en el ámbito de la Laguna de Fúquene) para $\mathrm{DBO}_{5}, \mathrm{DOO}$, nitrógeno como nitratos $\mathrm{NO}_{3}$ y fósforo como ortofosfatos $\mathrm{PO}_{4}$.

A partir de los resultados obtenidos, se proyectarán (en una siguiente fase), los parámetros para el diseño y construcción en terreno de un sistema con humedales artificiales, combinando procesos biológicos que involucren microorganismos y macrófitas, para optimizar la eficiencia en remoción de contaminantes de origen orgánico en vertimientos agroindustriales. 


\section{OBJETIVOS}

\subsection{Objetivo General}

Determinar la eficiencia de remoción de contaminantes orgánicos presentes en aguas residuales de hatos lecheros ubicados en un subsector de la laguna de Fúquene, a través de la implementación de tratamientos con 3 especies de macrofítas (del área de influencia del cuerpo de la lagunal, en humedales artificiales.

\subsection{Objetivos Específicos}

Caracterizar las aguas residuales provenientes de la actividad pecuaria en un subsector de la laguna de Fúquene.

Determinar a escala piloto la eficiencia de Eichhornia crassipes, Limnobium laevigatum y Typha domingensis, para la remoción de: Demanda Química de Oxígeno (DOO), Demanda Biológica de Oxígeno $\left(\mathrm{DBO}_{5}\right)$, nitrógeno como nitratos $\left(\mathrm{N}_{-} \mathrm{NO}_{3}\right)$, fósforo como ortofosfatos (P-PO $)$ y sólidos totales (ST); en los efluentes de hatos lecheros.

\section{MARCO TEÓRICO- CONCEPTUAL.}

\subsection{Humedales Artificiales}

Los humedales artificiales o terrenos pantanosos artificiales procuran idéntica capacidad de tratamiento que los humedales naturales, con la ventaja añadida de no estar sujetos a las limitaciones de vertidos a ecosistemas naturales. En los casos en los que se emplean para proporcionar tratamiento secundario o avanzado, los sistemas FSW suelen consistir en balsas o canales paralelos con el fondo construido por suelo relativamente impermeable o con una barrera subsuperficial, vegetación emergente, y niveles de agua poco profundos $(0.1$ a $0.6 \mathrm{~m})$.

Normalmente, se aplica agua residual pretratada de forma continua y el tratamiento se produce durante la circulación del agua a través de los tallos y raíces de la vegetación emergente. Los sistemas de flujo libre también se pueden diseñar con el objetivo de creación de nuevos hábitats para la fauna y flora, o para mejorar las condiciones de terrenos próximos. Esta clase de sistemas suele incluir combinaciones de espacios abiertos y zonas vegetales e islotes de las mismas (Cenagua. 1999)

Los humedales artificiales como sistema de tratamiento para aguas residuales crudas se han clasificado en función de la forma como el flujo pasa a través del sistema (Seoanes. M. 1999). Para el ensayo se siguieron los parámetros de diseño para una unidad de flujo horizontal superficial; sin utilización de ningún medio filtrante, donde el agua servida fluye en estos canales más o menos alargados, por gravedad. Esta clase de unidad puede ser dividida en dos subcategorías, teniendo en cuenta las especies de plantas acuáticas empleadas. Un primer grupo comprende principalmente las plantas emergentes, cuyo nivel de agua varía generalmente entre 100 y $500 \mathrm{~mm}$; mientras que el segundo grupo está compuesto por plantas flotantes cuyos niveles de agua varían desde 600 $\mathrm{mm}$ a $1 \mathrm{~m}$ (Cenagua. 1999) 
Los principales parámetros de diseño de los sistemas de plantas acuáticas incluyen el tiempo de retención hidráulica, la profundidad del agua, la geometría de las lagunas, la carga orgánica y la carga hidráulica; sin descartar la cinética del proceso. También se debe analizar el control de mosquitos y los tiempos y métodos de cosecha y procesado de las plantas extraídas (Crites $R \&$ Tchobanouglous. 2000)

\subsection{Efecto de los vertimientos ganaderos en los suelos.}

Los trabajos de investigación referenciados por Seoanes (1999), para la contaminación de los suelos por las actividades ganaderas indican que si bien es cierto que la disposición de los vertimientos de los estiércoles a través de irrigación mejora la estructura y estabilidad del suelo, es posible que simultáneamente que su disposición en exceso genere cambios rápidos en términos de potencial redox, favoreciendo la concentración de fósforo y nitrógeno, así como una mayor retención de humedad

El aumento de $\mathrm{pH}$ puede llegar a ser peligroso sí se alcanzan valores muy elevados (mayores de 8.0), como consecuencia del secado de las heces en potreros, si tarda en llover después de su aplicación, en este caso se produciría un efecto perjudicial para la actividad biológica del suelo y el desarrollo de las plantas.

El aporte de materia orgánica a los suelos hace que los productos añadidos sufran'una mineralización (paso de compuestos orgánicos nitrogenados a formas inorgánicas) y una nitrificación (paso de sales amónicas a nitritos y nitratos), convirtiéndolos a productos asimilables. En este último proceso también se verifica una oxidación de los $\mathrm{NO}_{3}-\mathrm{NO}_{2}$. Sí el aporte es muy intenso, por una parte pueden acumularse aminas y $\mathrm{NO}_{3}$ y formar nitrosaminas (productos cancerígenos) y por otra, ese nitrógeno añadido en forma de $\mathrm{NO}_{3}$ puede verse arrastrado debido a su alta solubilidad en el agua, con lo que, su disponibilidad disminuiría.

Una desnitrificación en la que se reducen $\mathrm{NO}_{3}$ o el $\mathrm{NO}_{2}$ a formas gaseosas puede provocar el mismo efecto, y el resultado es parecido sí aumenta el carbono disponible, al necesitar la desnitrificación un reductor. (Seoanes 1999)

\subsection{Caracterización de la Plantas Acuáticas utilizadas en el ensayo}

\subsubsection{Limnobium laevigatum}

Clase: monocotiledonia, familia: Hidrocharitoceae, biotipo: Acropleustofita, género: Limnobium, especie: laevigatum. Nombre vernáculo: Hoja Flotante, buchón bogotano. Especie distribuida generalmente en la Cordillera Oriental, en Cundinamarca y humedales naturales de la Sabana de Bogotá (Chaparro, B. 2003).

Planta propia de aguas profundas caducifolia perenne, poseen estolones y forman raíces en cada nudo; las hojas son ovales y están dispuestas en roseta y son de 10 a $30 \mathrm{~mm}$ de ancho, esponjosas, flores masculinas y femeninas separadas, sobre pedúnculos de un tercio o menos de la altura de las hojas, con tres sépalos y tres pétalos blancos. Propagación por fragmentación de los estolones y posiblemente por semilla. Temperatura mínima: $1^{\circ} \mathrm{C}$ - óptima de 18 a $28^{\circ} \mathrm{C}$ (Bristow, J.M. Et al. 1991) 


\subsubsection{Eichhornia crassipes}

Clase: Dicotiledonia, familia: Pontederiacea, biotipo: Acropleustofita, género: Eichhornia, especie: crassipes. Nombre vernáculo: Buchón o jacinto de agua.

Distribuida en ciénagas y lagunas del Valle del Cauca entre 100 y $1000 \mathrm{~m}$, en el bajo Magdalena, e igualmente en humedales andinos, cuenca de la laguna de Fúquene, Sabana de Bogotá, cuenca del río Bogotá sector alto, Soacha, Salto - Tibitoc y subcuenca del río Balsillas (Chaparro, B. 2003). Cubre la superficie de los cuerpos de aguas lénticas, por su alta tasa de propagación se desarrolla fácilmente en los márgenes de los humedales de acuerdo al estado de eutroficación.

Posee pecíolos esponjosos - aerènquimas - que actúan como flotadores. Posee estolones hasta de $1.2 \mathrm{~m}$ de largo con hojas de roseta con diámetro hasta de $23 \mathrm{~cm}$; pecíolos cortos e inflados en la base cuando la población de plantas es escasa o en plantas situadas en los bordes de las colonias, pero cuando la población es alta los pecíolos son largos y no están inflados en la base. Raíces fibrosas y modificadas; inflorescencia en forma de espiga con varias flores de color violeta o lila en los meses de agosto - septiembre. Propagación por estolones y probablemente por semillas. Nuevas infestaciones son causadas como resultado de la dispersión de las plantas por la acción del viento. Temperatura óptima del agua de $22-28^{\circ} \mathrm{C}$ y mínima $1^{\circ} \mathrm{C}$ (Rangel, O. 2003)

\subsubsection{Typha domingensis}

Clase : Monocotiledonia, familia: Typhaceae, biotipo: Helophyta, género: Typha, especie: domingensis. Nombre vernáculo: Enea, Anea.

Crece por lo general asociada con E. crassipes y en comunidades de Juncos densifforus y Sutellaria racemosa: distribución cordillera oriental, Cundinamarca, humedales de la Sabana de Bogotá: cuenca del río Bogotá en el sector Soacha - Tibotoc. Crea ambientes al borde del agua y en ocasiones islas flotantes donde viven y se reproducen aves acuáticas, además de curies que se alimentan de sus rizomas. Vegetación de pantano que crece en las orillas de las lagunas y charcos de la franja alta andina. Esta comunidad es encontrada en zonas donde se desarrollan actividades agropecuarias e industriales. Tolera grados avanzados de contaminación (Chaparro, B. 2003)

Posee hojas como lengûetas, provistas de tejido aerénquima que alcanzan $2 \mathrm{~m}$ de largo, provenientes de rizomas ramificados. Propágación por rizomas y estolones (Uribe, E. et al. 1997) 


\section{MARCO GEOGRAFICO}

\subsection{Localización del proyecto}

\subsubsection{Ubicación área de estudio.}

El mapa indica la localización de los hatos ganaderos seleccionados como zonas de muestreo dentro del contexto geográfico de la Laguna de Fúquene. De igual manera se estableció la georefeciacion para cada uno de los predios como se indica en la tabla No. 1

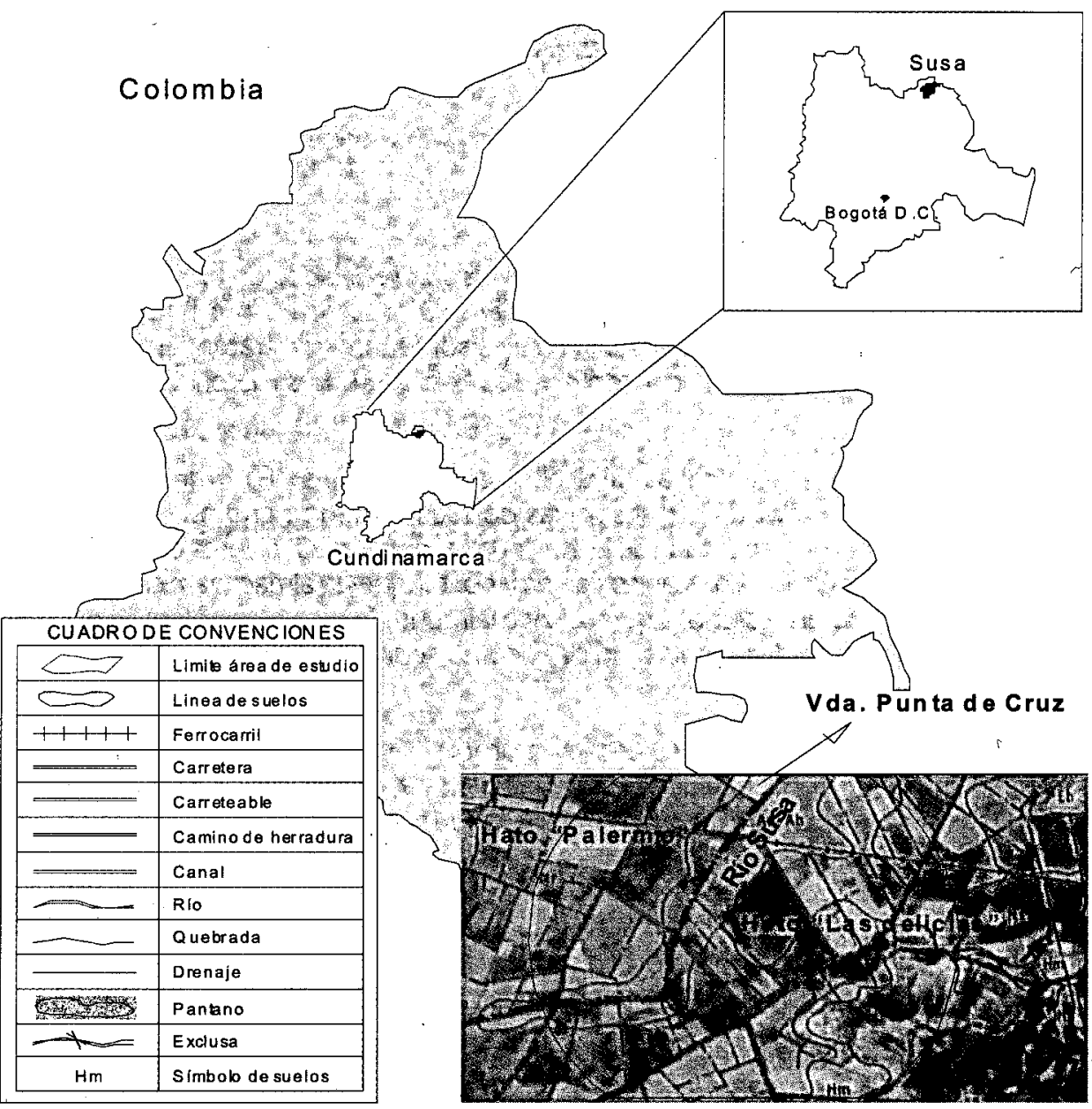


Tabla 1. Ficha Técnica hatos lecheros "Las delicias y Palermo"

\begin{tabular}{|c|c|c|}
\hline is & Hato "Las Delicias" & Hato Palermo \\
\hline Nivel freático aproximado & 4 a $6.5 \mathrm{~m}$ & 4 a $6 . \mathrm{m}$ \\
\hline Altitud & 2.568 m.s.n.m. & 2.560 m.s.n.m. \\
\hline Temperatura promedio & $14.94^{\circ} \mathrm{C}$ & $14.02^{\circ} \mathrm{C}$ \\
\hline Área & $30 \mathrm{Fg}$ & $16 \mathrm{Fg}$ \\
\hline \multirow[t]{3}{*}{ Densidad ocupacional } & 130 cabezas ganado & 150 cabezas ganado \\
\hline & 80 productoras. & 80 productoras \\
\hline & Raza Holstein. & Raza Holstein. \\
\hline Rendimiento pecuario & $60 \mathrm{Lt} /$ cabeza/día & 80 It/cabeza/día \\
\hline Producción diaria & $2.400 \mathrm{Lt}$ & $3.200 \mathrm{It}$ \\
\hline Caudal efluentes & 420 It/día & $400 \mathrm{lt} / \mathrm{dí} a$ \\
\hline \multirow[t]{2}{*}{ Punto de descarga } & Pozo estercolero & Pozo estercolero \\
\hline & $(\varnothing: 2 \mathrm{~m}-\mathrm{h}: 2.5 \mathrm{~m})$ & (0: $1.5 \mathrm{~m}-\mathrm{h}: 2.5 \mathrm{~m})$ \\
\hline
\end{tabular}

Fuente: El estudio (2004)

En los hatos anteriormente descritos, los ordeños son realizados dos veces por día (de 06:00 a 08:00am y de 16:00 a 18:00 pm), empleando como principal fuente de captación hídrica el agua del río Susa, la cual es sometida a un tratamiento de aireación por bandejas con carbón activado, filtrado con diferentes materiales y desinfección por clorado.

Los vertimientos analizados en los hatos lecheros "Las delicias y Palermo" son producto de la limpieza en las instalaciones físicas donde permanentemente se acumulan excrementos de las reses y residuos de leche. Igualmente procedimientos como el lavado y desinfección de los equipos mecánicos de ordeño, tanque de almacenamiento y demás componentes, generan residuos líquidos. Actualmente la fosa estercolera se está utilizando como depósito de captación inicial y como sedimentador o filtró de sólidos de gran tamaño.

Durante estos procedimientos se emplean productos detergentes líquidos de baja espuma, altamente concentrados en base a tensoactivos y secuestrantes orgánicos; como detergentes ácidos (Cow acid - impide la formación de piedra de leche en procesos lácteos), detergentes alcalinos (Cow lac - ataca rápidamente proteínas, carbohidratos, residuos secos y grasas, controla minerales de aguas duras) y soluciones desinfectantes /microsan - desinfectante catiónico de amplio espectro a base de biguanidina polimérical. Según protocolo de lavado empleado en el hato lechero "Las delicias", los cuales aportan contaminantes de origen químico a las aguas vertidas.

Además de los residuos antes descritos, se encuentran remanentes de piensos (cereales, melaza y algodón) los cuales son empleados durante el ordeño para la alimentación de las reses. 
Una vez colmatado el pozo estercolero, (cada quince días, en verano, y tres días en invierno, aproximadamente), es desocupado empleando el tanque estercolero o motobomba, irrigando en los potreros de pastoreo los vertimientos acumulados, conteniendo en mayor porcentaje residuos de heces vacunas.

\section{2 Suelos del área de estudio.}

Los suelos de los hatos lecheros seleccionados para el estudio, corresponden según el IGAC (Méndez, C. 1988), a la serie Nemocón: Arcilloso Profundo (NV) y Moderadamente Profundo (Ns) (ver mapa), teniendo en cuenta que son suelos pesados, moderadamente profundos, muy ácidos, pobres en nitrógeno, fósforo y potasio en su primer horizonte mineral; el agua freática es un factor limitante para el desarrollo de algunos cultivos.

Igualmente corresponden a suelos miscelaneos - tierra aluvial mezclada ( $\mathrm{Aa}$ - $\mathrm{Ab}$ ). En el primer horizonte se encuentran texturas franca, franco arcillosa, franco arcillo - limosa y arcillo - limosa, con un espesor que varía entre 20 y $30 \mathrm{c}$., y en donde dominan los colores claros. El subsuelo es de carácter liviano a mediano, escasamente pesado, de color dominante pardo amarillento se encuentra un horizonte liviano algo estratificado, de espesor y posición variables.

La topografía de esta unidad es ligeramente plana, con ligeras depresiones, lo que hace que esté sometida a encharcamientos cuya duración fluctúa entre 3 y 10 días y a desbordamientos ocasionales, que han obligado a los agricultores a usar sus tierras especialmente en ganadería, con buenos resultados. Generalmente el drenaje externo es lento a medio y el interno de medio a rápido. No presenta erosión.

La apreciación del análisis químico determina un suelo muy ácido, con capacidad de cambio mediana y bajo contenido de bases y saturación total. El calcio, el magnesio son pobres, el potasio regular y el sodio normal. El carbón orgánico es normal, el nitrógeno disponible y el fósforo son pobres. (Ménidez, C. 1988)

\section{METODOLOGIA}

\subsection{Primera fase: caracterización aguas residuales.}

La caracterización se realizó para evaluar la calidad de los vertimientos, en cuanto a parámetros físico-químicos se refiere, ya que no se contaba con referentes bibliográficos específicos para el agua residual de este tipo de agroindustrias en el área de estudio.

Se efectuaron ocho muestreos puntuales aproximadamente cada tres meses, desde enero de 2004 a mayo de 2005, condicionados a la climatología característica de la región: régimen bimodal de lluvias distribuidos en dos periodos húmedos: marzo - junio y septiembre - noviembre y dos periodos secos julio - agosto y diciembre - febrero; temperatura anual de $12-13^{\circ} \mathrm{C}$, humedad relativa de 76.54 , precipitación media anual de 753 mm (Cañón. J. 1996) 
Para el hato lechero "Palermo" se muestrearon dos puntos: área de almacenamiento de la leche y pozo estercolero. En "Las delicias" se muestrearon los vertimientos directamente del efluente en la caja de inspección antes de llegar al pozo estercolero. Se realizó medición in situ de $\mathrm{pH}$, temperatura y caudal.

Se realizaron pruebas de $\mathrm{DBO}$, $\mathrm{DOO}, \mathrm{N}-\mathrm{NO}_{3}, \mathrm{P}_{-} \mathrm{PO}_{4}$, y ST, como indicadores de contaminación orgánica, en el laboratorio de calidad de aguas de la Universidad Distrital Francisco José de Caldas, Facultad del Medio Ambiente y Recursos Naturales. Además se contó con una contra muestra realizada por Antek S.A.

Posterior a la caracterización de los efluentes de los dos hatos lecheros ubicados dentro del área de influencia de la laguna de Fúquene (margen izquierda y derecha del río Susal; se determinó este como punto crítico, debido a las altas concentraciones reportadas para $\mathrm{DQO}, \mathrm{DBO}_{5}, \mathrm{~N}-\mathrm{NO}_{3}, \mathrm{P}-\mathrm{PO}_{4}$ y ST. Considerando su cercanía con el rió Susa,

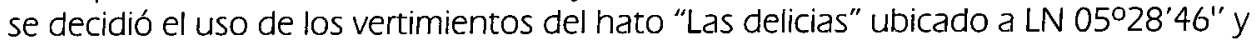
LW 73047'09', como afluente para el sistema piloto a escala.

\subsection{Segunda fase: determinación de la eficiencia en remoción de los tratamientos en sistema a escala piloto.}

El modelo estadístico aplicado fue un diseño de bloques completamente aleatorizados, con tres tratamientos y un testigo absoluto. Las unidades de los tratamientos se diseñaron manejando los parámetros para humedales artificiales de flujo horizontal superficial.

El sistema hidráulico de la planta piloto a escala, funcionaba por gravedad y contaba con un tanque de almacenamiento (volumen 220 It), dentro del cual se acondicionó una trampa de sólidos en malla de acero inoxidable; un sedimentador con pendiente de $2 \%$; un canal en zinc distribuidor de caudal, y cuatro unidades piloto para los tratamientos. Todo el sistema interconectado entre sí, con manguera hidráulica de 1/2" de diámetro. El caudal por goteo se mantuvo empleando válvulas de paso, calibradas durante múltiples ensayos antes de la puesta en marcha del experimento. Ver ilustración 2.

El agua residual fue recolectada de la caja de inspección antes de llegar al pozo estercolero, evitando que se mezclara con vertimientos anteriores y posteriormente transportada desde el efluente de origen (hato lechero "Las delicias") hasta el lugar del ensayo construido en la sede el vivero de la Universidad Distrital ubicado a LN 04035 '49.5" LW $74^{\circ} 03^{\prime} 52.5^{\prime \prime}$ y 2703 m.s.n.m, contando con similares condiciones climáticas a las del área de estudio.

Se determinó un tiempo de retención hidráulico aproximado a quince días para el ensayo a escala piloto, teniendo en cuenta las condiciones reales del hato (tiempo de residencia en el pozo estercolero).

Eichhornia crassipes, Typha domingensis y Limnobium laegivatum fueron las especies seleccionadas para el estudio. El material vegetal fue extraído de laguna de Fúquene, en la desembocadura del río Ubaté, tributario con elevada carga contaminante, garan- 


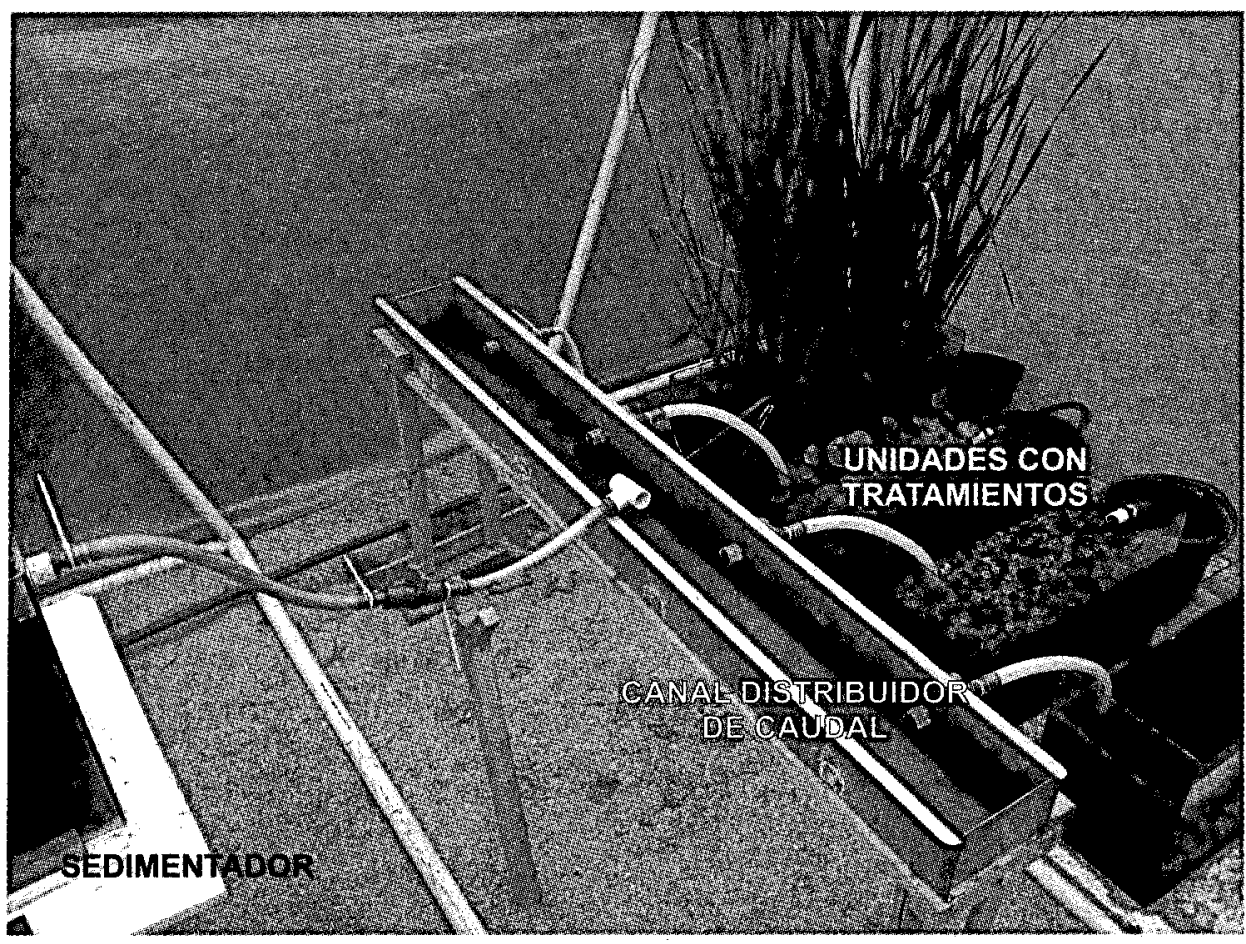

Ilustración 2. Sistema a escala piloto.

tizando así la adaptabilidad de las mismas a altas concentraciones contaminantes de origen orgánico. Se ubicaron agrupaciones vegetales localizadas en las siguientes coordenadas geográficas: Eichhornia crassipes LN: 05026'26", LW: 73045'07", Typha. domingensis LN: 0526'41", LW: 73045'08", Limnobium laevigatum LN: 05026'41", LW: $73^{\circ} 45^{\prime} 04^{\prime \prime}$

Como criterio de selección se extrajeron plantas en etapa temprana de crecimiento, debido a que en este estado los individuos nuevos son quienes han logrado mejor adaptación al medio por estar expuestos a altas concentraciones de contaminantes orgánicos e inorgánicos. La selección del número de individuos de cada especie se realizó teniendo en cuenta el porcentaje de cobertura vegetal que estos ocuparían dentro de las unidades experimentales, para E. crassipes 10 individuos cada uno con 4 hojas, de $2 \mathrm{~cm}$ de diámetro; L. laevigatum, 20 individuos de $1 \mathrm{~cm}$ de diámetro y agrupaciones de 4 hojas; y T. domingensis, 10 individuos de longitud entre 20 y $25 \mathrm{~cm}$, de 5 a 7 hojas por estolón. 
Tabla 2. Componente hidráulico del sistema a escala piloto.

\begin{tabular}{|c|c|c|c|c|c|}
\hline $\begin{array}{l}\text { Componentes del } \\
\text { sistema }\end{array}$ & $\begin{array}{l}\mathrm{vT} \\
(\mathrm{m})\end{array}$ & $(\mathrm{ml} / \mathrm{min})$ & $\begin{array}{l}\text { TRH } \\
\text { (días) }\end{array}$ & $\mathrm{cog} \mathrm{COV}^{3}$ & $\begin{array}{l}P^{5} \\
(\mathrm{~cm})\end{array}$ \\
\hline Sedimentador & 91200 & 10.15 & & & \\
\hline Canal & 64800 & 10.15 & & & \\
\hline Unidad E. crassipes & 54000 & 2.54 & 14.7 & 0.13 & 24.70 \\
\hline Unidad L. laevigatum & 54000 & 2.54 & 14.7 & 0.13 & 19.05 \\
\hline Unidad Testigo & 54000 & 2.54 & 14.7 & 0.13 & 0 \\
\hline Unidad T. domingensis & 72000 & 2.54 & 19.7 & 0.10 & 30.00 \\
\hline
\end{tabular}

${ }^{1}$ Volumen total. Área húmeda (VT)

${ }^{3}$ Tiempo de retención hidráulico (TRH) (COV)

${ }^{5}$ Profundidad Radicular

(PR)
${ }^{2}$ Caudal de entrada (CE)

${ }^{4}$ Carga orgánica volumétrica

Previo al arranque y operación del sistema y posterior al sembrado del material vegetal, se realizó una estabilización de la biomasa empleando agua potable con anticloro. eliminando remanentes de contaminación del lugar de origen. Inicialmente se colmó el tanque de almacenamiento con 220 it de agua residual cruda y el sedimentador con 91.2 It de la misma, alimentando el sistema de forma continua, desplazando totalmente el agua de acondicionamiento. Este procedimiento se realizó antes del primer muestreo, para obtener una adaptación paulatina de las plantas lacustres a los vertimientos objeto del estudio. Posterior al contacto de las macrófitas con el agua residual, se regularon por goteo, empleando válvulas de paso, los caudales de entrada para el sedimentador, el canal y las unidades, asegurando un TRH de quince días en el tratamiento.

A partir de la regulación de los caudales, el sistema fue alimentado cada quince días con agua residual del hato lechero "Las delicias", seleccionado como afluente. Quincenalmente, previo al llenado del tanque de almacenamiento, se tomaban muestras de las unidades experimentales, durante un periodo de tres meses (cinco repeticiones). El seguimiento durante toda la fase experimental del sistema piloto a escala se llevó a cabo evaluando los parámetros empieados para la caracterización de las aguas residuales crudas, durante 90 días, muestreando quincenalmente los efluentes, posteriores a la etapa de estabilización del material vegetal.

Se realizó análisis descriptivo, obteniendo promedios y varianzas de los tratamientos y de los datos de la caracterización del hato lechero "Las delicias"; comparación de medias y análisis de varianza con una prueba ANOVA de una vía y prueba de Tukey (para un $\alpha<0.05$ ) y porcentajes de remoción de los tratamientos para cada parámetro analizado, frente a los datos del testigo absoluto: 


\section{RESULTADOS Y DISCUSIÓN}

\subsection{Primera fase: caracterización aguas residuales.}

En la tabla 3, se identifican los datos promedio obtenidos de los análisis en laboratorio para los tres puntos de muestreo, en los dos hatos lecheros seleccionados para la caracterización de los vertimientos de éste tipo de agroindustria.

Tabla 3. Resultados promedio de los parámetros físico - químicos del agua residual hatos lecheros "Palermo" y "Las delicias".

\begin{tabular}{c|c|c|c|}
\hline Hato Lechero & Las deliclas & \multicolumn{2}{|c|}{ Palermo } \\
\hline Parámetro & Pozo estercolero & Area Alm. Leche & Pozo estercolero \\
\hline Temperatura ${ }^{\circ} \mathrm{C}$ & 13.76 & 13.8 & 14.16 \\
\hline $\mathrm{pH}$ & 9.01 & 6.7 & 7.65 \\
\hline $\mathrm{DBO}_{5} \mathrm{ppm}$ & 1095.46 & 124.16 & 909.41 \\
\hline $\mathrm{DOO}^{\mathrm{ppm}}$ & 2822.29 & 1882.33 & 2570 \\
\hline $\mathrm{NO}_{3} \mathrm{ppm}$ & 7.67 & 2.75 & 6.78 \\
\hline $\mathrm{PO}_{4} \mathrm{ppm}$ & 13.68 & 5.81 & 12.67 \\
\hline $\mathrm{ST} \mathrm{ppm}$ & 566 & 199.13 & 382.63 \\
\hline
\end{tabular}

Fuente: el estudio (2005)

Para la caracterización de los efluentes se tomó como referencia lo estipulado en el Decreto 1594 de 1984 emitido por el Ministerio de Salud, el cual reglamenta el uso del agua y residuos líquidos, determinando que según los parámetros analizados, este tipo de aguas residuales no pueden ser dispuestas en cuerpos de aguas o irrigación sin previo tratamiento.

Además, para vertimientos dispuestos directamente sobre suelos, no se cuenta con una normatividad vigente para Colombia que regule o limite la cantidad. de Nitrógeno procedente de estiércoles o purines que se pueda emplear como fertilizante o esparcir por unidad de área en zonas de pastoreo, los cuales por sobrecarga de nutrientes en ciertos períodos del año podrían causar contaminación (toxicidad) en los pastizales.

\subsection{Segunda fase: determinación de la eficiencia en remoción de los tratamientos en sistema a escala piloto.}

Las variables externas como las condiciones ambientales (altitud, temperatura, y precipitación) fueron monitoreadas durante la caracterización en el área de estudio (subcuenca de la laguna de Fúquene), y al ser comparadas con la climatología del lugar donde se ubicó el piloto, se registraron datos similares, por lo cual se infiere que dichas variables fueron controladas. Igualmente fueron controladas las variables dependientes al ensayo (Tiempo de Retención Hidráulica, Caudal de Entrada, Volumen total, tamizado o ponderación de la población, área de cobertura vegetall.

Como resultado de la evaluación a cada uno de los tratamientos se establecieron los promedios para los parámetros físico químicos como se indica en la tabla No. 4. 
Tabla 4. Resultados promedio de los parámetros físico - químicos para los efluentes de los tratamientos.

\begin{tabular}{c|c|c|c|c}
\hline Tratamientos & E. crassipes & 1 laevgatum & T domingensis & Testigo absoluto \\
\hline Parámetros & & & & \\
\hline Temperatura & 17.34 & 17.54 & 17.46 & 17.44 \\
\hline $\mathrm{pH}$ & 8.05 & 8.11 & 8.34 & 9.01 \\
\hline $\mathrm{DBO}_{5}(\mathrm{ppm})$ & 140.71 & 116.91 & 149.12 & 408.18 \\
\hline $\mathrm{DQO}(\mathrm{ppm})$ & 272.80 & 322.40 & 428.00 & 522.40 \\
\hline $\mathrm{NO}_{3}(\mathrm{ppm})$ & 2.2 & 3.2 & 3.2 & 4.4 \\
\hline $\mathrm{PO}_{4}(\mathrm{ppm})$ & 8.28 & 12.38 & 13.36 & 12.94 \\
\hline $\mathrm{ST}_{(\mathrm{ppm})}$ & 72.90 & 118.70 & 115.00 & 154.60 \\
\hline
\end{tabular}

El gráfico l demuestra que al inicio del ensayo hubo una adaptación positiva del material vegetal empleado ya que a los 15 días de operación del piloto (primer muestreo) todos los tratamientos reportaron una concentración de $\mathrm{DBO}_{5}$ menor a la del testigo absoluto. Esto posiblemente se deba a que el lugar de extracción del componente vegetal está expuesto a altas cargas de contaminación. Igualmente, se observó que todos los tratamientos se comportaron de una forma global definida durante el tiempo del ensayo.

Gráfico 1. Comportamiento de $\mathrm{DBO}_{5}$ durante el tiempo del ensayo para cada uno de los tratamientos.

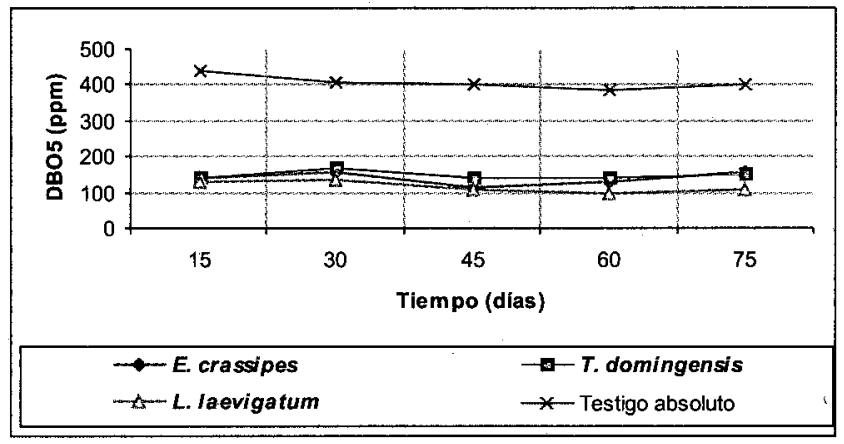

Comparando el promedio obtenido con el hato lechero "Las delicias" (1095.46 ppm). vertimientos tomados como afluente para la planta piloto a escala, con los promedios obtenidos en los tratamientos (ver tabla 4), se determinó la degradación de materia orgánica por las macrófitas empleadas, las cuales son capaces de sintetizar biomasa como sustrato (Ronzano, E. 1995), corroborado en la disminución de las concentraciones de $\mathrm{DBO}_{5}$ en los tratamientos empleando material vegetal.

Sin embargo, disminuyó considerablemente la concentración de $\mathrm{DBO}_{5}$ por parte del testigo absoluto, probablemente debido al empleo de un sedimentador como pretratamiento para todo el sistema, (donde se decantaban los sólidos de mayor tamaño), creando un medio propicio para la reproducción microbiana, aumentando así la síntesis de materia orgánica por parte de microorganismos originarios de las aguas residuales 
de este tipo de agroindustria, los que asimilaron gran parte de materia orgánica contenida en los vertimientos analizados.

Esto permitió evidenciar al momento de realizar los análisis de la $\mathrm{DBO}_{5}$, donde no fue necesario emplear inoculó pues para este tipo de aguas con altas concentraciones de materia orgánica-y población microbiana, el adicionamiento de bacterias es inoperante ya que saturaría la muestra (ICONTEC. NTC 3680)

Por lo tanto se asume que, debido a que la cantidad de oxígeno disuelto en el agua es directamente proporcional a la $\mathrm{DBO}_{5}$; así como disminuyó la cantidad de materia orgánica biológicamente degradable, también disminuyó el valor de oxígeno disuelto como resultado de la respiración microbiana y de los procesos propios de la degradación orgánica en el agua.

Gráfico 2. Comportamiento de DQO, duránte el tiempo del ensayo para cada uno dé los tratamientos.

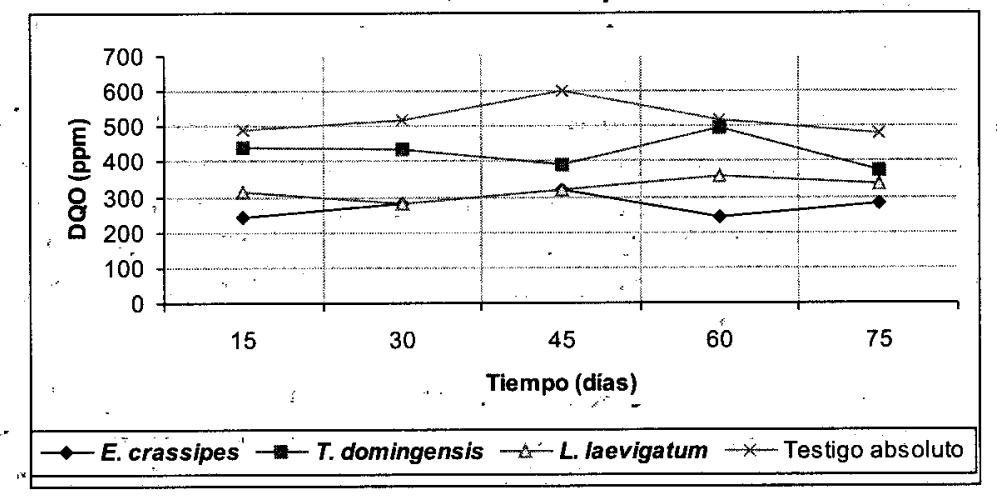

En la gráfica 2, para DOO, el tratamiento coń L. laevigatum fue el único que mantuvo una distribución simétrica a lo largo del ensayo, llegando al máximo de asimilación para el día 30. Sin embargo E. crassipes fue el tratamiento que alcanzó mayor valor de DOO, demostrando desde el comienzo del ensayo adaptación positiva al agua residual, reflejado en las bajas concentraciones (ppm).

En el tratamiento con T. domingensis posterior a un periodo de estabilización lentre 15 - 30 díasl, disminuyeron las concentraciones para el muestreo del día 45, alcanzando el máximo de remoción en el muestreo a los 75 días. Probablemente debido a los tamizados realizados para el segundo y cuarto muestreo. Igualmente el aumento de las concentraciones de DOO para el día 60, se puede explicar como un aumento de sustancias químicas reductoras (material oxidable) presentes en el agua tratada, bien sea de origen orgánico o mineral (Ryding, S. \& Rast, W. 1992).

La disminución de $\mathrm{DBO}_{5}$ y $\mathrm{DOO}$, con el empleo de estos dos tratamientos (L. laevigatum y E. crassipes), puede entenderse como el resultado de la síntesis de materia orgánica presente en el agua residual, empleada por las plantas como fuente de nutrientes para su crecimiento y desarrollo; sin descartar la posible simbiosis de microorganismos 
presentes tanto en el agua como en las raíces de las macrofítas utilizadas en el experimento.

Gráfico 3. Comportamiento de $\mathrm{PO}_{4}$, durante el tiempo del ensayo para cada uno de los tratamientos.

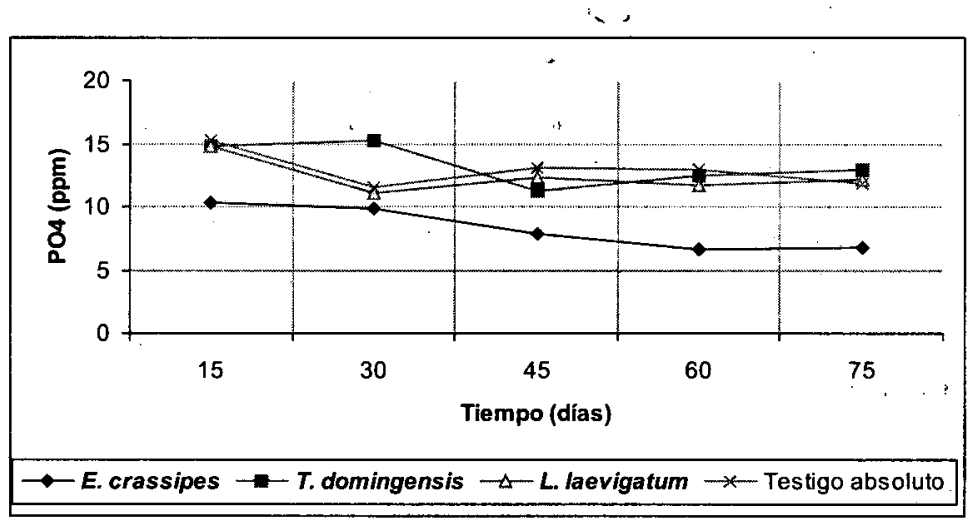

Al igual que la materia orgánica y otros elementos, el ortofosfato $\left(\mathrm{P}_{-} \mathrm{PO}_{4}\right)$ es fundamental para el desarrollo de las plantas que también puede generarse como desecho dentro de procesos biológicos como fitotratamientos y/o biotratamientos, posterior a la asimilación de materia orgánica contenida en aguas residuales (Campillo, N. 1993). Razón por la cual los valores de $\mathrm{PO}_{4}$ de los tratamientos no disminuyeron representativamente, como se observa en la gráfica 3.

A partir de los 30 días del ensayo se observó que los tratamientos con E. crassipesy T. domingensis disminuyeron las concentraciones de $\mathrm{PO}_{4}$; demostrando una adaptabilidad de las macrófitas al agua residual analizada; sin embargo el tratamiento con $E$. crassipes fue el único que demostró una remoción positiva. Probablemente debido a que éste elemento $\left(\mathrm{P}_{-} \mathrm{PO}_{4}\right)$ al principio no provoca ni participa en reacciones de oxidoreducción y su solubilidad en el agua és baja cuando aparece en moléculas orgánicas o en forma de ortofosfatos (Seoanes, M. 2003)

Sin embargo el tratamiento empleando $T$. domingensis mantuvo concentraciones superiores a las del testigo absoluto corroborando lo descrito por Metcalf \& Eddy (1995) donde se afirma que las tifáceas no eliminan fósforo puesto que no absorben este elemento; además las macrófitas enraizadas dependen, en mayor medida, de los nutrientes de los sedimentos del fondo, que de los de la columna de agua (Ryding. S. $\&$ Rast, W. 1992); esto se evidencia en el aumento de las concentraciones de $T$. domingensis, con respecto a las del testigo absoluto.

L. laevigatum, mantuvo un comportamiento estable e inferior al del testigo absoluto, finalizando con concentraciones similares a las del control. Lo anterior probablemente debido a la saturación de esta macrófita de $\mathrm{PO}_{4}$, posterior a su asimilación máxima a los 60 días. 
Gráfico 4. Comportamiento de $\mathrm{NO}_{3}$, durante el tiempo del ensayo para cada uno de los tratamientos.

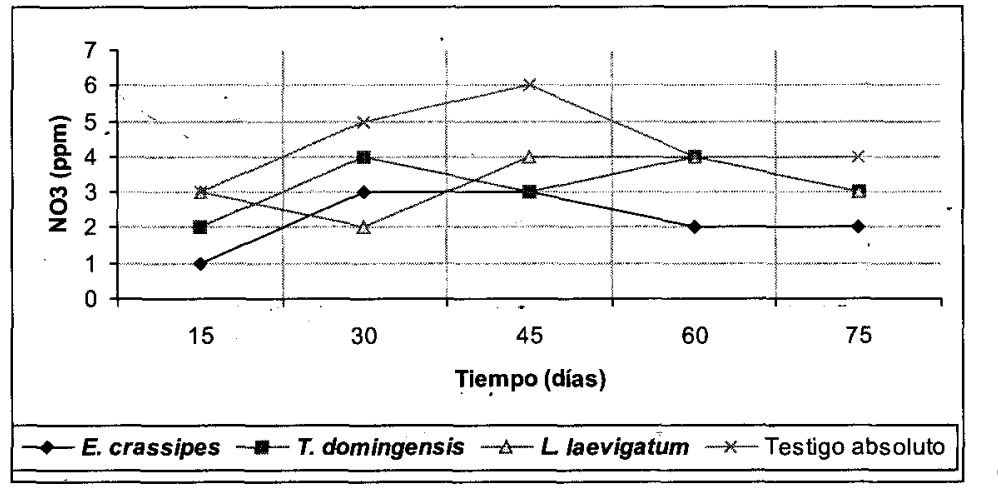

En las unidades de tratamiento empleando E. crassipes y $T$. domingensis, al igual que la del testigo absoluto, hubo un aumento en las concentraciones de $\mathrm{NO}_{3}$ entre los días 15 y 30 del.estudio; probablemente debido a la aparición de algas cianofíceas ${ }^{5}$ en dichas unidades, aproximadamente a los 20 días de inicio del ensayo, la proliferación de algas ocurre en tiempos cortos, dependiendo de la cantidad de las formas biológicamente disponibles de fósforo y nitrógeno (Ryding, S. \& Rast, W. 1992).

Como resultado de un mejor proceso de oxido-reducción en medio saturado y anaerobio, y la constante asimilación de materia orgánica a expensas de la reducción de nitratos generando amoniaco $-\mathrm{NH}_{4}-$ (Castillo, J. 1990), el tratamiento empieando $E$. crassipes fue el que representó una mayor asimilación del nitrógeno como nitratos; en comparación con los otros tratamientos.

A partir del día 45, posteviour a un periodo de estabilización, la unidad con E. crassipes demostró un incremento gradual de asimilación de $\mathrm{NO}_{3}$, finalizando con un periodo aceptable de degradación de éste elemento.

L. laevigatum aunque para el día 30 mostró su máximo de asimilación, a lo làrgo del estudio, no preśentó mejor respuesta aumentando las concentraciones de $\mathrm{NO}_{3}$; jor lo tanto se considera que el tratamiento empleando esta macrófita no es eficiente en el momento de remover nitrógeno residual.

Para el día 45 del estudio, el testigo absoluto demostró una disminución de las concentraciones de $\mathrm{NO}_{3}$, de 6 a 4 ppm; hasta asemejar los valores de L. laevigatum y $T$. domingensis, para posteriormente estabilizarse. Lo anterior debido à que lós nitratos tienen un alto grado de movilidad, desplazánidose fácilmente por corrientes superficiales acuosas (Seoanes, 1999), produciendo una disminución de concentraciones, más aún teniendo en cuenta que se implementó un diseño hidráulico para unidades de flujo horizontal superficial, èl cual trabaja por gravedad.

5 Microorganismos indicadores de contaminación, fijadores de nitrógeno (nitrificadores), presentes mayormente en aguas estancadas y en reposo abundantes en compuestos nitrogenados diluidos (amonio). Castillo, José. Química General. Universidad Nacional de Colombia. Fac. Ingeniería Química. Paimira - Valle. 1990. 
Gráfico 5. Comportamiento de los sólidos totales, durante el tiempo del ensayo para cada uno de los tratamientos.

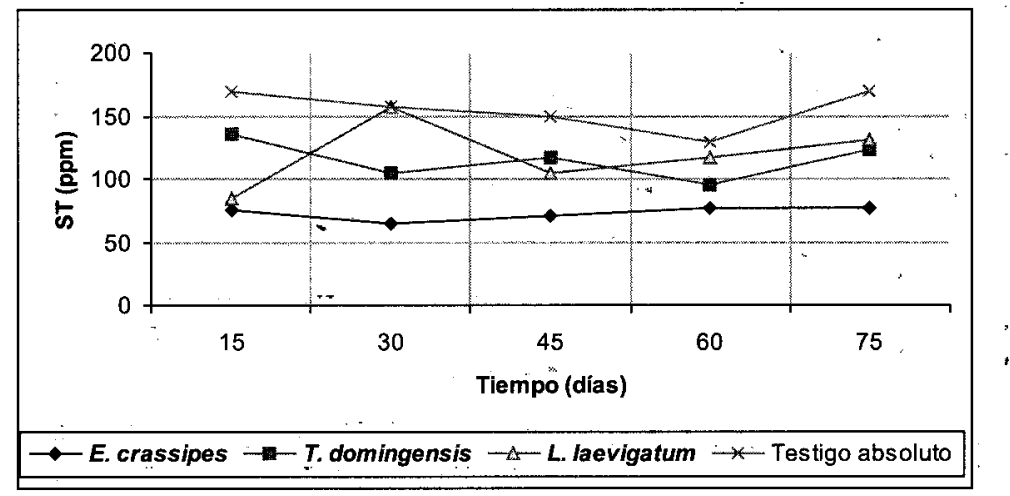

E. crassipes a través del ensayo, demostró una tendencia central alcanzando su máximo de retención de ST a los 30 días del inicio del estudio, siendö el tratamiento óptimo para retención de sólidos: Igualmente el tratamiento empleando "T. domingensis. mantuvo un comportamiento estable, llegando a su máxima absorción a los 60 días. Este tratamiento empleando'macrófitas emergentes demostró positiva absorción, probablemente debido a sus características biológicas, donde las raíces colmaban el área húmeda de la unidad experimental, permitiendo mayor contacto del agua con la parte radicular. Sin embargo, los resultados obtenidos"con T. domingensis no son mejores que los reportados para E. crassipes, teniendo en cuenta que según Ryding \& Rast (1992) las plantas emergentes dependen en mayor medida, de los nutrientes encontrados en los sedimentos del fondo, más que de los de lá columna de agua, volviéndose menos sensibles que otras macrófitas (para este caso 'L. laevigaturíl) a variaciones de nutrientes.

Debido a la inestabilidad de la especie L. laevigatum se presentó una desviación marcada hacia el segundo muestreo, pasando de su máximo de asimilación a un punto crítico (alcanzando las concentraciones del testigo absoluto), manifestado en una adaptación negativa a aguas residuales con altas concentracioneș de sólidos en suspensión desde el inicio del ensayo. Así mismo se aprecian continuas fluctuaciones de los valores reportados, indicando que éste tratamiento no proporciona aceptable remoción para éste parámetro.

La conductividad eléctrica (CE) proporciona una medida de la cantidad de sólidos totales disueltos ionizados en las muestras, teniendo en cuenta que aumenta proporcionalmente a la cantidad de sólidos disueltos en el agua (Fanson, M. 1992); y al comparar los valores de la conductividad eléctrica de los vertimientos de hato "Las delicias" (403 $\mu \mathrm{s}$ ) frente los datos obtenidos de los tratamientos, se observa que después de $E$. crassipes, $T$. domingensis (tabla 5) fue el segundo tratamiento mejor adaptado para retener sólidos totales disueltos en el agua analizada, verificando que efectivamente el tratamiento empleando $T$. domingensis, es adecuado para la remoción de ST. 
Tabla 5. Conductividad eléctrica / sólidos disueltos totales para los tratamientos.

\begin{tabular}{|c|c|c}
\hline Tratamientos & TDS $(\mathrm{ppm})$ & CE $(\mu \mathrm{s})$ \\
\hline E. crassipes & 1.83 & 3.75 \\
\hline T. domingensis & 1.88 & 3.99 \\
\hline L. laevigatum & 1.94 & 4.01 \\
\hline Testigo absoluto & 2.15 & 4.33 \\
\hline
\end{tabular}

Fuente: El estudio 2005.

Igualmente la disminución de las concentraciones de ST para todos los tratamientos (incluyendo el testigo absoluto), valida la funcionalidad del sedimentador implementado como pretratamiento para todo el sistema, el cual retuvo sólidos de gran tamaño. incrementando la eficiencia del material vegetal, además de homogenizar el afluente; alcanzando una remoción de sólidos cercana al 30\%, comparando las concentraciones de los vertimientós del hato lechero "Las delicias" (566 ppm de ST), con las obtenidas en el testigo absoluto (154.60 ppm de ST); resultando favorable la implementación de un sedimentador como pretratamiento en el diseño de humedales artificiales empleando alguna de éstas macrófitas.

Gráfico 6. Comportamiento del $\mathrm{pH}$, durante el tiempo del ensayo para cada uno de los tratamientos.

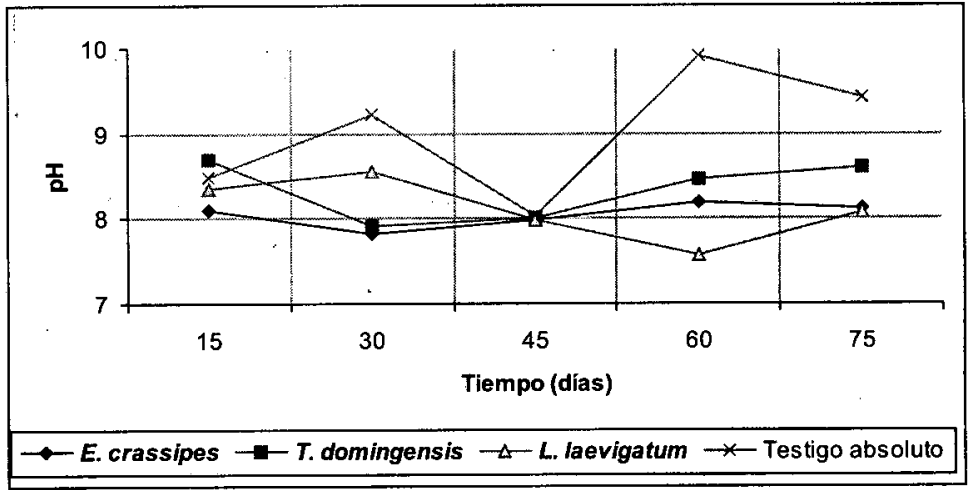

En general, los valóes obtenidos para el pH (gráfica 6) durante los muestreos de los afluentes del ensayo presentaron situaciones atípicas dentro de la tendencia, más aún para el testigo absoluto.

Debido a que dentro del protocolo de lavado y desinfección para los equipos e instalaciones físicas del hato lechero "las delicias", mensualmente, se hace desinfección general empleando detergentes surfactantes alcalinos, con material fosfórico ${ }^{6}$ (adición del

- Los álcalis constituyen la base de la mayor parte de los detergentes que se usan en lechería. los cuales pueden actuar por ataque directo a las proteínas, disolviéndolas, saponificando las grasas y actuando después como agente hipotensor (humectante), emulsor y suspensor, y que los jabones formados aumentan el poder del detergente y la temperatura de la solución. Keating Patrick y Gaona Homero. Introducción a la lactología. Editorial Limusa.' España. 1999 
producto Multigras los días 15 y 45 del ensayol, aumentaron los niveles de $\mathrm{pH}$ para los días 30 y 60 en la unidad del testigo absoluto ( 9.22 y 9.91 , respectivamente), al existir una analogía entre el incremento de la temperatura, producido por la saponificación de proteínas y formación de jabones en el medio acuoso (Keating, P. \& Gaona, H. 1999) y el $\mathrm{pH}$.

Igualmente en el testigo absoluto, para los días 15, 45 y 75 del ensayo, posterior a la adición de desincrustante (días 0,30 y 60 ), el pH tiende a acidificarse en aguas sin ningún tipo de tratamiento.

Sin embargo, en las unidades empleando material vegetal, las plantas pueden llegar a estabilizar tanto el $\mathrm{pH}$ como la temperatura del agua residual, evidenciándose lo anterior, en el comportamiento del tratamiento con $E$. crassipes, el cual durante todo el estudio se mantuvo con una tendencia central sin variaciones marcadas.

Para el caso de L. laevigatum, se observa un comportamiento atípico para los días 30 y 60, que indican la inestabilidad de esta planta cuanto hay fluctuaciones de $\mathrm{pH}$ en la columna de agua.

Gráfico 7. Comportamiento de la temperatura durante el tiempo del ensayo para cada uno de los tratamientos.

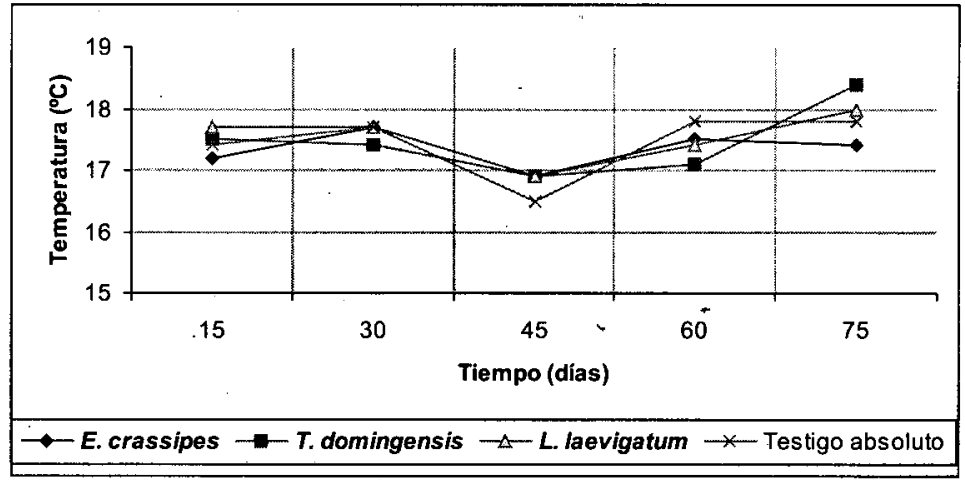

Al igual que el $\mathrm{pH}$, la temperatura, para los casos de las unidades con macrófitas, reportó una forma global definida dentro de la tendencia central, indicando una estabilización de la temperatura en agua tratada, que podría atribuirse al empleo de material vegetal como tratamiento.

La liberación de energía en forma de calor es un indicador de crecimiento y desarrollo de microorganismos, resultado de sus procesos bioquímicos, tales como toma de nutrientes, transporte y asimilación de los mismos, fotosíntesis entre otros; los cuales intervienen directamente en tratamientos biológicos (Caicedo, B. 2002); posiblemente la adición del producto "microsan" (desinfectante catiónico de amplio espectro) que tendía efectos inhibitorios en el crecimiento de microorganismos, afectó la población microbiana que actúa como agente biodegradante, presente en las aguas residuales, disminuyendo la temperatura para el día 45 del ensayo en todas las unidades experi- 
mentales. Igualmente, para el caso de los tratamientos con macrófitas, este descenso de temperatura pudo deberse al tamizado realizado el día 30, que permitió mayor aireación en la lámina de agua superficial.

Al finalizar el estudio (muestreo día 75), la tendencia general de los tratamientos fue un aumento de temperatura, probablemente al incremento del componente biológico en las aguas tratadas (crecimiento y reproducción microbiana y de algas cianofíceas); aumentando la solubilidad de la mayoría de las sales nutritivas ( $N$ y P) presentes en dichos vertimientos.

Tabla 6. Coeficientes de variación por parámetro analizado, para los tratamientos.

\begin{tabular}{|c|c|c|c|c|}
\hline & \multicolumn{2}{c}{ Coeficiente de Variación (Tratamientos) } & \\
\hline Parámetro & E crassipes & T domingensis & Llaevigatum & Testigo absoluto \\
\hline $\mathrm{DBO}_{5}$ & 12.29 & 7.50 & 12.81 & 4.59 \\
\hline $\mathrm{DQO}$ & 10.67 & 9.82 & 8.14 & 8.01 \\
\hline $\mathrm{NO}_{3}$ & 38.03 & 26.15 & 26.15 & 25.91 \\
\hline $\mathrm{PO}_{4}$ & 21.06 & 12.62 & 11.11 & 10.94 \\
\hline Sólidos Totales & 7.08 & 13.33 & 22.77 & 10.92 \\
\hline
\end{tabular}

Como parte del análisis estadístico se calcularon los coeficientes de variación (tabla 6) para cada parámetro y cada uno de los tratamientos, los cuales demostraron valores bajos, indicando menor variación en los datos y mayor homogeneidad en los resultados, consecuencia del adecuado control de las variables tanto dependientes como independientes al ensayo.

\subsection{Análisis de varianza "anova" para una vía, prueba de tukey y porcentajes de remoción.}

A partir de los resultados obtenidos para los efluentes anteriormente descritos, se realizó un análisis de varianza y comparación de medias para una vía, con cuatro tratamientos organizados en un diseño experimental de bloques simples al azar y cinco repeticiones o muestreos; determinando diferencias significativas entre los cuatro tratamientos, para cada uno de los parámetros analizados. La prueba de Tukey determinó cuál de los tratamientos reportó mayor remoción de carga contaminante para los vertimientos analizados. Pruebas realizadas con el paquete estadístico SAS, para una media poblacional de cinco $(n=5)$ y un intervalo de confianza del $95 \%(\alpha<0.05)$.

Los resultados obtenidos (tabla 7), además de corroborar la información descrita en eí análisis estadístico descriptivo; determinaron los tratamientos con mayor efectividad en la remoción de cada uno de los parámetros analizados; siendo E. crassipes la especie más adecuada para el empleo en fitotratamientos de aguas residuales del: tipo de agroindustria analizada: 
Tabla 7. Tratamientos con mayor remoción por cada parámetro analizado.

\begin{tabular}{|l|c}
\hline Parámetro analizado & Tratamiento Imacrófital \\
\hline $\mathrm{DBO}$ & \multicolumn{1}{|c|}{ L. laevigatum } \\
\hline $\mathrm{DOO}$ & $\ddots$ E. crassipes \\
\hline $\mathrm{NO}_{3}$ & E. crassipes \\
\hline $\mathrm{PO}_{4}$ & E. crassipes \\
\hline Sólidos Totales & E. crassipes \\
\hline
\end{tabular}

Igualmente $L$ l laevigatum, puede llegar a proporcionar eficiente depuración de materia orgánica; teniendo en cuenta que para el caso específico de $\mathrm{DBO}_{5}$ presentó la mayor remoción; mientras que $T$. domingensis, al contrario de los otros tratamientos, estadísticamente no reporta aceptable asimilación de los contaminantes analizados. Sin embargo, puede que $T$. domingensis sea funcional para facilitar la depuración de sólidos totales, como se observa en la tabla 8 (25.61\% de remoción para ST), gracias al enmarañamiento de su parte radicular y a su capacidad de asimilación de nutrientes a partir de sustrato.

Tabla 8. Porcentajes de remoción de los tratamientos con macrófitas.

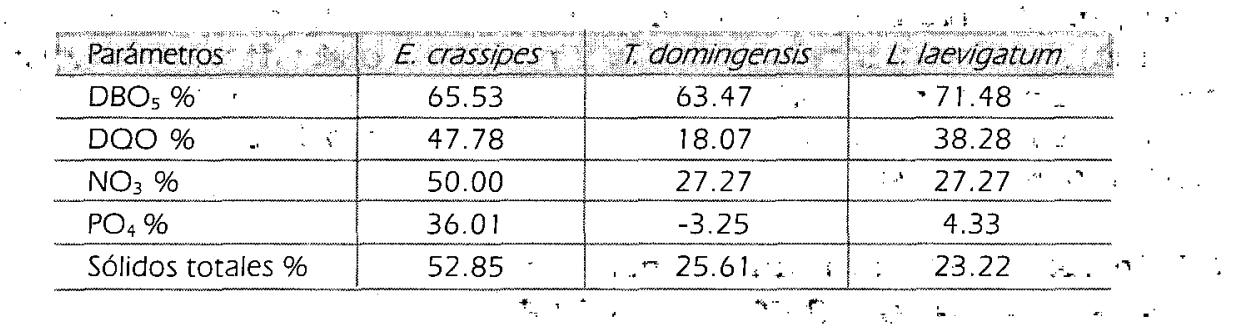

El análisis èstadístico evidenció inconfundiblemente que, a excepción del $\mathrm{PO}_{4}$, el testigo absolúto no sobrepasó los resultados obtenidos de los tratamientos, lo cual determina que el estudio aporta información veraz para la implementación de humedales artificiales en el tratamiento de aguas residuales con características similares a las analizadas.

\subsection{Otros resultados.}

6.4.1 Tamizado en las unidades experimentales.

El tamizado de las plantas acuáticas es necesario para mantener un cultivo con elevada asimilación de nutrientes; así mismo, se removieron individuos durante el funcionamiento del sistema, manteniendo la población inicial, asegurando la homogeneidad en los tratamientos, y teniendo en cuenta que estas especies en condiciones adecuadas de nutrientes tienden a reproducirse rápidamente colmatando el cuerpo de agua donde habitan, evitan el intercambio de oxígeno del agua con el medio, generando un medio anaerobio, con tendencia a la nitrificación de cuerpos de agua; además, el exceso de plantas genera cortocircuitos en el fluido desde la entrada hasta la salida en las unidades. 
Para el segundo muestreo (día 30), se removieron 12 plantas de E. crassipes, cada una con ocho pecíolos y anexas a los estolones, cuatro plantas nuevas de $5 \mathrm{~cm}$ de diámetro. Para Typha domingensis que reportó un crecimiento longitudinal de $40 \mathrm{~cm}$ a 1.20 $\mathrm{cm}$, engrosamiento en los estolones y en las hojas con aumento en el numero de las mismas y un notable cambio en la pigmentación del foliaje; se extrajeron seis plantas en estado degenerativo manteniendo la población inicial, Igualmente se eliminaron 22 individuos en estado de descomposición de Limnobium laevigatum, manteniendo 20 individuos.

El día 60 șe repitió éste procedimiento para las tres macrófitas, observando que díchas plantas crecen manteniendo la anterior proporción dentro de las unidades experimentales.

En cuanto a la recuperación y usos de la biomasa, que de no manejarse adecuadamente puede transformarse en.un problema; Novotny $\&$ Olem (1994) Moore (1995) y Metcalf $\&$ Eddy (1995) señalan que la cosecha de los tratamientos con macrófitas se puede incorporar como fertilizante directamente sobre la tjerra o mediante compost, o bien usarla en la manufactura de cartón, en la producción de combustible, usando material seco y liviano en la forma de briquetas y mediante gasificación de la biomasa para la producción de biogás. También como material absorbente de colorantes y metales: pesados.

\subsection{2 "Tanque de almacenamiento.}

Dentro del tanque de almàcenamiento se dispusó una rejilla con el fin de àtrạăar sólidos de gran tamaño. Debido al colmado de la reja, fue necesario remover los sólidọ atrapados, compuestos, básicamente por residuos de piensos y heces vacunas."

Se tomó el peso húmedo de dichos sólidos (2.160 gr) y posterior al desecado a temperatura ambiente, el peso.secó (75் gr). La diferencia de pesos (1.402 gr) representa el nivel de agua evaporada de los sólidos extraídos. El peso seco resultante, equivale a la cantidad de sólidos contenidos en el agua residual, los cuales nunca entraron al sistema.

\subsubsection{Presencia de mosquitos y otros insectos:plaga.}

A lo largo del estudio no hubo presencia significativa de mosquitos dentro del lugar adecuado para el ensayo, indicando ausencia de olores fuertes producidos por descomposición de materia orgánica (Ácido Sulfhídrico - $\mathrm{H}_{2} \mathrm{~S}$ ), al igual que remanentes de heces sobre el agua en tratamiento en todo el sistema piloto a escala, ya que las larvas de insectos pastorean sobre piedras y plantas removiendo algas y bacterias que están creciendo, además de nutrirse de agua contaminada por un método de filtración.

No se evidenciaron otros insectos plaga en el lugar de estudio, en comparación con los sitios de toma de muestras y lugares de recepción del agua residual analizada (fosa estercolera hato lechero "Las delicias"), donde és evidente la presencia de estas poblaciones de vectores.

\subsection{4 ... Presencia de algas cianofíceas o azulverdosas.}

En las paredes y el piso de las cuatro unidades del piloto, crecieron poblaciones de algas cianoficeas. Aproximadamente para el día 20, de inicio del ensayo se hicieron visibles las primeras agrupaciones de algas cianofíceas. 
La presencia de algas cianofíceas en las unidades experimentales se reflejó en un incremento de $\mathrm{NO}_{3}$, debido a que dichos microorganismos fijan nitrógeno atmosférico a reservas de agua.

\section{CONCLUSIONES.}

- Los vertimientos de los hatos lecheros analizados, presentan altas concentraciones de carga contaminante (1095.46 ppm de $\mathrm{DBO}_{5}$ y 2822.29 ppm de DOO), por lo cual es necesario la implementación de un sistema de tratamiento para este tipo de residuos líquidos.

- El ensayo empleando Eichhornia crassipes, reportó mayor eficiencia para el tratamiento de aguas residuales de hatos lecheros, alcanzando remociones hasta de un $65 \%$.

- Limnobium laevigatum, logró remover un,54.8\% en promedio, de materia orgánica representada como $\mathrm{DOO}$ y $\mathrm{DBO}_{5}$, siendo el segundo tratamiento en asimilación de contaminantes.

- Los tratamientos con L. laevigatumy T. domingensis, para la depuración de fósforo como ortofosfatos, no aportaron una asimilación representátiva, en comparación con los porcentajes de remoción obtenidos para los otros parámetros analizados.

- Por su parte, Typha domingensis nio demostró éficiencia representativa én remoción de contaminantes, excepto para sólidos totales donde alcanzó un $25.61 \%$.

- Es necesaria la implementación de un sedimentador como pretratamiento; dentro un sistema de humedales artificiales, para optimizar el saneamiento de aguas residuales de hatos lecheros.

- La presencia de algas cianofíceas en las unidades experimentales aumentó la concentración de $\mathrm{NO}_{3}$ en el agua residual tratada:

- Es viable debido al mínimo gasto energético, alta efectividad y economía de mantenimiento, la implementación de humedales artificiales alternando Eichhornia crassipes, Limnobium laevigatumy Typha domingensis, como șistema de tratamiento de aguas residuales crudas de hatos lecheros.

\section{RECOMENDACIONES}

- Realizar análisis específicos para la identificación de microorganismos biodegradantes presentes en los vertimientos, con el fin de determinar su posible viabilidad en la implementación de un tratamiento conjunto con macrófitas, para aguas residuales de este tipo.

- Se recomienda realizar pruebas físico-químicas al efluente del sedimentador con el fin de evaluar su eficiencia. 
- Es indispensable realizar pruebas de nitrógeno en todas sus etapas $\left(\mathrm{NH}_{2}-\mathrm{NH}_{3}, \mathrm{NO}_{2}\right.$, $\mathrm{NO}_{3}$ ), con el fin de analizar la capacidad de remoción del sistema para estos compuestos.

AGRADECIMIENTOS:

Al Centro de Investigaciones y Desarrollo Científico de la Universidad Distrital Francisco José de Caldas, quien financió la ejecución del proyecto, por medio del grupo de investigación PROGRAPS. A los docentes Carlos Valencia y Gloria Acosta, par evaluativos internos del Proyecto curricular de tecnología en saneamiento ambiental

\section{BIBLIOGRAFÍA}

JICA - Agencia japonesa para la cooperación internacional. Corporación autónoma regional de Cundinamarca (CAR). Estudio sobre plan de mejoramiento ambiental regional para la cuenca de la laguna de Fúquene. Informe final. Bogotá. 2000.

BRISTOW, J.M. \& Et Al. . Malezas acuáticas. Instituto colombiano agropecuario e internacional. Plant Protection Center. Oregon State University / Agencia internacional para el desarrollo. Bogotá D.C., Colombia. 1991.

CAICEDO, C. Correal Cuervo, Rodrigo - Compilador. Tratamiento y postratamiento de aguas residuales. Centro de investigaciones para el desarrollo. Ediciones Uniboyacá. 2002.

CAMPILLO, N. Análisis de aguas - aire. Edición Universidad Pontificia Bolivariana. Facultad de ingeniería química. Medellín, Colombia. 1993

CAÑón, J. "Recuperación y descontaminación de la laguna de Fúquene" Publicación: Asamblea de Cundinamárca. Bogotá D.C. 1996

CASTILLO, J. Química General. Universidad Nacional de Colombia. Facultad de ingeniería química. Palmira, Valle. 1990.

Centro nacional del agua (CENAGUA), Organización panamericana de la salud (OPS), Société Québécioce D'assanissement des Eaux. Sistemas de tratamientos de aguas servidas por medio de humedales artificiales. Bogotá. 1999.

CHAPARRO, B. Los humedales de Bogotá y la Sabana. Reseña de la vegetación en los humedales de la Sabana de Bogotá. Subdirección de patrimonio ambiental. Corporación Autónoma Regional de Cundinamarca (C.A.R). Publicación: Acueducto de Bogotá y conservación Internacional. Colombia. 2003.

CRITES, Ron \& Tchobanouglous. Sistemas de tratamiento de aguas residuales para núcleos pequeños y descentralizados. Edit. McGraw - Hill. México D.F. 2000

FANSON, M.. Métodos normalizados para análisis de aguas potables y residuales. APHA, AWNWA, WIPCF. Edit. Diaz de Santos S.A. Madrid, España. 1992.

ICONTEC. Equivalente para Norma Técnica Colombiana: NTC 4758 buenas prácticas del laboratorio, NTC 3680 DBO, NTC 3629 DOO, NTC $4798 \mathrm{NO}_{3}$. 
KEATING P. y Gaona H. Introducción a la lactología. Editorial Limusa. España. 1999

MÉNDEZ, C. P. Suelos de Ubaté - Chiquinquirá. Estudio detallado del valle y general de la Zona. Instituto Geográfico Agustín Codazzi. IGAC. Bogotá. 1988.

METCALF \& Heddy, Ingeniería de aguas residuales: tratamiento, vertido y reutilización. Mc Graw-Hill. España. 1995.

MOORE, T. R., Bubier, J. L. Methyl and-total mercury in boreal wetland plants, Experimental lakes area, Northwestern Ontario. J. Environ. Qual. 1995

MORALES, E. Publicación: Colombia ciencia y tecnología. Vol 4. “Potencial de plantas acuáticas en el tratamiento de aguas residuales". Bogotá. 1991.

MURGUEITIO, E. Sistemas de producción ganadera y sus impactos en la transformación de los ecosistemas andinos de Colombia. Memorias del seminario internacional sobre transformación de ecosistemas. Universidad Javeriana. Bogotá. Colombia. 2002.

NOVOTNY, $\mathrm{V}$. and Olem, H. Water quality: prevention, identification and management of diffuse pollution. Van Nostrand Reinhold, New York. 1994

Publicación: Cultura del agua No. 3. Humedales artificiàles. Corporación Autónoma Regional de Cuñdinamarca (CAR). Bogotá. 2000.

RANGEL, O. Los humedales de Bogotá y La sabana. El antiguo lago de La sabana de Bogotá. Instituto de Ciencias Naturales. Universidad Nacional de Colombia. Publicación acueducto de Bogotá y conservación Internacional. Colombia. 2003.

RONZANO, E. Dapena J. Tratamiento biológico de las aguas residuales. Ediciones Díaz de Santos S.A. España. 1995

RYDING, Sven - Olof. \& Rast Walter. El control de la eutrofización en lagos y pantanos. UNESCO. Edit. Pirámide S.A. Madrid. España. 1992:

SANTOS, E. Fúquene. El Lecho de la Zorra. Corporación Autónoma Regional de Cundinamarca (CAR) División de recursos naturales. Bogotá. 2000.

SEOANES, C., M. Aguas Residuales: tratamiento por humedales artificiales. MC GrawHill. México 1999.

SEOANEZ, C. Mariano. Manual de tratamiento, reciclado, aprovechamiento y gestión de las aguas residuales de las industrias agroalimentarias. Ediciones Mundi-prensa. Madrid. España. 2003

URIBE, E. Osorio, J. Molina, L. Cerros, humedales y áreas rurales de santafé de Bogotá. DAMA. 1997 